\title{
Defensive medicine in Italy: a nationwide survey
}

\author{
[Massimiliano Panella , Fabrizio Leigheb, Chiara Donnarumma and Carmela Rinaldi] ${ }^{1}$ \\ University of Eastern Piedmont \\ Italy
}

\begin{abstract}
Introduction: Defensive Medicine (DM) affects healthcare systems worldwide. The concerns and perception about medical liability could lead practitioners to practise defensive medicine. The role of other possible determinants remains mostly unclear. Objective: to assess the prevalence of the practice of DM among Italian hospital physicians, its costs, and its determinants. Methods: Cross-sectional web survey was conducted. Main Outcome Measures: number of physicians reporting to have engaged in any DM behaviour in the last year. Results: 1,313 physicians completed the survey. 685 physicians stated that they practise DM. Almost all the respondents believed that DM would increase in the near future. $46.5 \%$ of the interviewed expected to adopt more DM within the next year. Most of the interviewed physicians believed that practising DM would reduce their risk of being sued for malpractice; they also believed DM is not harmful to their patients. DM absorbed $10.71 \%$ of the total national health expenditure of Italy, with an estimated total cost of about $\mathbf{\epsilon 1 1 . 6 0}$ billion per year. Malpractice reform, together with a systematic use of evidence-based clinical guidelines, has been indicated to be the most effective solution for reducing DM. Conclusions: $D M$ is a significant factor in healthcare costs without adding any benefit to patients. The economic burden of DM on healthcare systems should provide a substantial stimulus for a prompt review of this situation in a time of economic crisis.
\end{abstract}

Keywords-Defensive Medicine, Medical Malpractice, Health Care Costs.

\section{Introduction}

Defensive medicine (DM) has been defined as a deviation from sound medical practice that is induced primarily, but not solely, by the threat of liability claims [1, $2,3,4]$. DM consists of two behaviours, one that may supplement care ('positive' DM) and the other that involves avoidance behaviour to distance doctors from sources of legal risks ('negative' DM) [5, 6, 7]. In the United States, 93\% of physicians reported practising DM in a hospital, and $78 \%$ of hospital doctors in the United Kingdom and $60 \%$ in Israel practised DM in a hospital $[2,4,7]$. The percentage of doctors practising DM is higher for some specialties, including, obstetrics and gynaecology (97\%), gastroenterology (94-98\%), neurosurgery (75-83\%), and orthopaedics and traumatology $(96 \%)[5,8,9,10,11,12$, $13,14,15,16,17]$.

The practice of DM is a significant financial burden in healthcare systems. In the United States, DM is estimated to cost US \$50-100 billion annually [18, 19]. At the patient level, the practice of DM was also estimated to cost hospitals US\$226, which is the $13 \%$ of the mean patient cost (US \$1,695) [20].

In Italy, national data about the practice of DM is lacking $[10,21,22]$. The objectives of this study were to assess the prevalence of the practice of DM among Italian hospital doctors and its costs.

\section{Methods}

\section{Study design}

A quantitative survey was implemented as a web questionnaire. The Italian Ministry of Health and the National Healthcare Agency for Regional Health Services deemed that ethical approval for this study was unnecessary, because it was a physicians survey and no patients were included. The opening page of the survey provided information about the scope and purpose of the study and contained a mandatory sub-section that explicitly requested consent to each physician. The participants' consents were not recorded since this was a de-identified anonymous online survey.

\section{Sample}

A list of candidate physicians for inclusion was drawn from the human resources databases of 55 hospitals in Italy. Appropriate sample size was estimated based on $65 \%( \pm 5)$ expected prevalence of DM. The minimum required sample size was determined to be 927 participants to achieve a 0.05 type I error rate and $90 \%$ power.

\section{Survey questionnaire}

The survey questionnaire was based on the results of a previous systematic literature overview of the definition, use, and impact of DM [6]. A multidisciplinary team with expertise in clinical and risk management developed the questionnaire in March 2014. The resulting draft questionnaire was pilot tested for validity on 25 physicians, with an inter-test interval of 15 days between the first and the second validation tests (Pearson's $r=0.8$ ). None of the 25 physicians used in the validation participated in the main survey study. Four questions were modified, and one question was added as a result of this pilot testing.

The final version of the questionnaire was composed of 44 items divided into four sections. One section collected demographic information, and other sections posed direct and indirect questions about practising DM, reasons for practising DM, and questions on possible strategies to minimise the practice of DM. Respondents were asked to rank their behaviours related to the practice of DM. and to rate their frequencies on an 11-point scale. Respondents followed the same procedure in answering the questions on the causes of DM and ways to minimise the need to practise it. In addition, respondents were asked to express their opinion about the impact of the practice of DM on their patients and on the healthcare system level, including their opinion about the possible future adoption of their practising DM.

\section{Survey administration}


Proc. of The Fifirth Intl. Conf. On Advances in Economics, Management and Social Study - EMS 2016

Copyright (C) Institute of Research Engineers and Doctors, USA .All rights reserved.

ISBN: 978-1-63248-089-7 doi: 10.15224/ 978-1-63248-089-7-32

We carried out the survey between April and June 2014. We randomly invited 1,500 physicians to complete the survey. The invitation email contained a link to an anonymous web-based questionnaire. Reminder invitation were sent every month during the data collection period. No incentives was provided for participation. The study was carried out in accordance with the Italian national laws and regulations that govern personal privacy [23].

\section{Statistical analysis}

Each quantitative variable was summarised as a mean value and standard deviation. To summarise qualitative variables, frequencies and percentages were used.

\section{Cost analysis}

Estimates of the costs associated with the practice of DM were determined directly, according to the typologies of the adopted DM and to the volumes of patients treated by each respondent as measured in the physicians' self-reported behaviour.

\section{Results}

1,313 completed questionnaires were analysed (92.14\% response rate). Table 1 shows the characteristics of the participants.

785 physicians $(59.79 \%$; 95\%CI, 57.09-62.47) stated that they practise one kind of or a combination of kinds of DM surveyed in the questionnaire. Table 2 summarises the kinds of DM behaviours seen in the daily practice of the physician respondents.

Regarding the reasons for practising DM, the respondents perceived as a major determinant a general negative context surrounding negligence claims against physicians. Specifically, 234 physicians ranked inadequate legislation for protecting doctors' rights $(29.81 \%)$ as the top reason for practising DM, and another 222 physicians indicated fear of medical lawsuits $(28.28 \%)$ as a reason. Forty-nine physicians $(6.24 \%)$ stated they were concerned about medical injury compensation for malpractice, and 22 physicians $(2.80 \%)$ feared compromising their professional reputation and or career.

108 respondents $(13.76 \%)$ perceived that an ineffective physician-patient relationship was the most important cause of DM. Forty-two physicians (5.35\%) indicated unfavourable mass media and public attitude towards medical behaviours as causes, and 56 physicians $(7.13 \%)$ indicated inadequate medical and or organisational procedures as reasons for practising DM. Other perceived causes included inadequate liability insurance coverage (13 respondents, $1.66 \%$ ) and inadequate hospital support for liability issues (39 respondents, 4.97\%).

First, confirm that you have the correct template for your paper size. This template has been tailored for output on the US-letter paper size. If you are using A4-sized paper, please close this file and download the file for "MSW A4 format".

Massimiliano Panella, Fabrizio Leigheb, Chiara Donnarumma and Carmela Rinaldi

University of Eastern Piedmont Italy
TABLE I. DEMOGRAPHIC CHARACTERISTICS OF PHYSICIAN RESPONDENTS

\begin{tabular}{|c|c|c|}
\hline \multicolumn{2}{|c|}{ Characteristics } & \multirow{2}{*}{$\frac{\mathbf{n}(\%)}{273(20.79)}$} \\
\hline Age range (years) & $20-40$ & \\
\hline & $41-50$ & $300(22.85)$ \\
\hline & $51>$ & $740(56.36)$ \\
\hline \multirow[t]{2}{*}{ Gender } & Female & $519(39.53)$ \\
\hline & Male & $794(60.47)$ \\
\hline \multirow[t]{3}{*}{ Years of experience } & $<=5$ & $125(9.52)$ \\
\hline & $6-15$ & $329(25.06)$ \\
\hline & $\geq 16$ & $859(65.42)$ \\
\hline \multirow{3}{*}{$\begin{array}{c}\text { Activity volume } \\
\text { (procedures/visits per } \\
\text { week) }\end{array}$} & $0-30$ & $424(32.29)$ \\
\hline & $31-70$ & $628(47.83)$ \\
\hline & $\geq 71$ & $261(19.88)$ \\
\hline \multirow[t]{2}{*}{ Risk of specialty* } & High risk & $526(40.06)$ \\
\hline & Low risk & $787(59.94)$ \\
\hline \multirow[t]{2}{*}{ Practise DM? } & Yes & 785 (59.79) \\
\hline & No & $528(40.21)$ \\
\hline
\end{tabular}

TABLE II. DESCRIPTION AND FREQUENCY OF THE PRACTICE OF DEFENSIVE MEDICINE AMONG PHYSICIAN RESPONDENTS

\begin{tabular}{|l|l|}
\hline \multicolumn{1}{|c|}{ Specific practices of defensive medicine } & \multicolumn{1}{c|}{$\begin{array}{c}\text { Percentage* } \\
\text { (n=785) }\end{array}$} \\
\hline $\begin{array}{l}\text { Refer to specialists in unnecessary } \\
\text { circumstances }\end{array}$ & $16.59 \%(16.88)$ \\
\hline Order more lab tests than medically indicated & $21.87 \%(19.62)$ \\
\hline $\begin{array}{l}\text { Order more diagnostic tests or procedures than } \\
\text { medically indicated }\end{array}$ & $22.75 \%(19.48)$ \\
\hline $\begin{array}{l}\text { Prescribe more medications than medically } \\
\text { indicated }\end{array}$ & $11.18 \%(17.50)$ \\
\hline $\begin{array}{l}\text { Refer patients to emergency room in } \\
\text { unnecessary circumstances }\end{array}$ & $6.41 \%(18.44)$ \\
\hline $\begin{array}{l}\text { Admit/transfer patients to hospital in } \\
\text { unnecessary circumstances }\end{array}$ & $5.18 \%(18.97)$ \\
\hline Avoid caring for high-risk patients & $4.31 \%(20.32)$ \\
\hline $\begin{array}{l}\text { Avoid conducting effective high-risk } \\
\text { procedures/interventions }\end{array}$ & $5.85 \%(19.61)$ \\
\hline
\end{tabular}

${ }^{*}$ Weighted rates (standard deviation).

Almost all the respondents believed that the practice of DM would increase in the near future (94.65\%). When asked about their own practice, $46.50 \%$ of the physicians stated that they expected to adopt more DM practices in the next year.

As can be seen in Table 3, 46 physicians who practised DM believed it to be helpful for their practice because DM was perceived as a protection against the risk of being sued for malpractice $(43.44 \%)$. Other physicians believed that practising DM could lead to more effective medical decision making (28.21\%), better physician-patient relationships $(15.14 \%)$, more appropriate care $(13.02 \%)$, or better working climate $(6.49 \%)$. 110 physicians believed that DM had a positive effect on their patients, because it increased patient satisfaction $(40.04 \%)$, it put patients' needs at the centre of medical care $(22.73 \%)$, and it reduced patients' risk $(22.73 \%)$. They also stated that DM provided the patients with better access to care $(10.04 \%)$ and that employing DM behaviours are more effective in treating complex patients $(4.51 \%)$. The majority of the sample (507 
physicians) reported that the practice of DM reduced the risk of medical lawsuits by $31.09 \%$ (SD: $24.81 \%$ ). The great majority of the sample believed that DM could significantly increase costs in the healthcare system.

We estimated that the total cost of DM is $€ 165.40$ per capita per year. Since the national mean health expenditure is $€ 1,847.36$ per capita per year in Italy, this meant that the practice of DM accounted for $10.71 \%$ of the total national health expenditure. This translates to an estimated total cost of about $€ 11.60$ billion per year. The practice of DM generated $14.61 \%$ of the annual cost for drugs, $10.99 \%$ of the cost for specialists, $22.86 \%$ of the cost for lab tests, and $24.85 \%$ of the cost for diagnostic procedures. The interviewed physicians attributed a significant share of the estimated costs to patients and families, who demanded the tests $(24.15 \%)$.

Physician respondents were also asked to identify possible solutions to reduce the practice of DM. Solutions were proposed on a professional level, everyday practice level, and healthcare system level. For everyday practice, almost half of the physicians $(48.22 \%)$ identified the systematic use of evidence-based medicine and organised care (clinical pathways, protocols, etc.) as the most effective solutions for reducing DM. This was followed by more attentive, daily communication with patients and families $(18.13 \%)$ and with other colleagues in multidisciplinary team collaborations $(4.57 \%)$. Implementation of a more systematic education to continuously improve physicians' knowledge and skills was also highly ranked (16.16\%). Other possible solutions offered were better management of clinical records $(5.53 \%)$, strengthening physicians' ethical values $(4.68 \%)$, use of better risk management procedures $(1.91 \%)$, and implementation of systematic clinical auditing and medical debriefing $(0.92 \%)$.

At the system level, most of the physicians believed that malpractice reform is the most effective action to reduce the practice of DM $(52.96 \%)$. A more favourable public attitude towards physicians was also perceived as an important factor to reduce DM. This included more favourable public and mass media attention and emphasising good results of everyday medicine, instead of highlighting malpractice and medical errors $(15.53 \%)$; employing incentives for good practices (14.89\%); and instituting stronger protection of physician's rights by employers $(13.22 \%)$ and insurance companies $(3.26 \%)$.

TABLE III. PHYSICIAN RESPONDENTS' PERCEIVED IMPACT OF DEFENSIVE MEDICINE (DM) (N=785 ANSWERS)

\begin{tabular}{|c|c|c|c|}
\hline \multirow{2}{*}{ Outcomes of DM } & \multicolumn{3}{|c|}{ No. of respondents (\%) } \\
\cline { 2 - 4 } & Yes & No & $\begin{array}{c}\text { No } \\
\text { difference }\end{array}$ \\
\hline $\begin{array}{c}\text { Positive impact on physicians' } \\
\text { practice }\end{array}$ & $\begin{array}{c}46 \\
(5.86 \%)\end{array}$ & $\begin{array}{c}540 \\
(68.79 \%)\end{array}$ & $\begin{array}{c}199 \\
(25.35 \%)\end{array}$ \\
\hline $\begin{array}{c}\text { Positive impact on patient care } \\
\text { Increase in the costs of medical } \\
\text { care }\end{array}$ & $\begin{array}{c}675 \\
(85.99 \%)\end{array}$ & $\begin{array}{c}341 \\
(43.44 \%)\end{array}$ & $\begin{array}{c}334 \\
(42.55 \%)\end{array}$ \\
\hline \multicolumn{2}{|c|}{$\begin{array}{c}\text { Reduction in the risk of } \\
\text { medical lawsuits }\end{array}$} & $507 \%)$ & $\begin{array}{c}109 \\
(13.88 \%)\end{array}$ \\
\hline \multicolumn{2}{|c|}{$(64.58 \%)$} & $(1.53 \%)$ & $\begin{array}{c}266 \\
(33.89 \%)\end{array}$ \\
\hline
\end{tabular}

\section{Iv. Discussion}

This study was the first nationwide, broad-scope survey on physicians' opinions on the practice of DM in Italy. Italy is a nation that has been significantly affected by the escalation of liability and insurance costs [10, 26, 27].

In our study, we observed a $58.78 \%$ prevalence of practising DM, which is lower than reported in other studies $[2,4,8,9,10,13]$. This was probably due to our sample composition, which included a significant portion of physicians working in less risky specialities [7].

Our findings show a higher prevalence of positive DM, which was significantly more adopted then negative DM. These results are consistent with those in the literature $[2,4$, $5,7,16]$. Surprisingly, only a small number of physicians stated that they prescribe more medications than medically indicated [4]. During the last decade, Italian physicians experienced increasingly greater pressure to improve the appropriateness of drugs they prescribe, with the goal of reducing drug expenditures. This phenomenon could probably explain our findings. In fact, in a self-report survey format on DM practices, physicians may have been more motivated to provide socially desirable responses in order to achieve the appearance of reaching a political goal [2]. We also observed a significantly lower use of negative DM than reported in the literature. Again, this can be due to the respondents giving socially desirable answers, thereby understating the true frequency of the kinds of DM that could seem harmful. However, we believe that our results show low use of negative DM practices, because of our mixed sample composition [4]. In fact, in studies focussing on high-risk specialties, negative DM was significantly higher $[2,9,10,11,12]$.

In line with previous national and international studies, our physicians perceived the possibility of malpractice litigation as the major driver of DM practices $[2,4,5,7,8$, $10,12,13,24]$. A recurring theme in our study is that DM exists because physicians have a fear of being sued for malpractice and related issues. Even if this notion is overestimated by physicians [25], we believe this is an important issue that needs to be addressed, because physicians want protection against liability risk [24].

Our findings reveal how the practice of DM accounts every year for approximately $10 \%$ of the total Italian national health expenditure. Our results are consistent with other studies that assessed the cost of DM on the healthcare system budget, both on the aggregate and patient levels [5, $10,13,19,20]$. This means that the practice of DM could represent one of the major causes of the budget deficit of the Italian National Health Service over recent years. We also expect that such costs will increase, since half of our sample of physicians stated that they would adopt more DM behaviours in the next year. Although other studies have argued that DM is not a major factor in rising healthcare costs, our data showed that the costs of DM clearly are a major problem $[13,18]$.

It is important to notice that a significant portion of our sample did not perceive any possible negative effect of the practice of DM on patients. In our opinion, this could be a serious concern. As in similar studies, our physicians reported ordering unnecessary diagnostic and lab tests, referring patients to unnecessary consultants, etc. Simple 
diagnostic testing can be annoying and costly but is typically not harmful to most patients. On the contrary, other procedures and treatment, as well as negative DM, can expose patients to serious risks, cause significant harm, and cost a lot of money $[4,7,11]$.

For everyday practice, physicians in our survey suggested that the systematic use of EBM methods would be the best strategy to reduce DM, together with employing better communication with patients and their family. This is consistent with findings in the literature, which recommend disseminating clinical guidelines and quality-improvement initiatives that incorporate clinical pathways, and to educate patients and physicians about appropriate care [2, 9, 22]. The need for directives and other methods for transparency in providing care emerged, therefore, as the best everyday action to prevent or minimise the practice of DM. This finding was quite surprising for Italy, where huge efforts have been made during the last 20 years to encourage the use of evidence [28]. This probably means that the actual level of guideline implementation in the National Healthcare System is still suboptimal, or at least not effective enough to avoid DM. In fact, guidelines and related methods like clinical pathways still represent a generalisation of empirical evidence that may not always be applicable to individual patients and/or adopted by legislators [8, 10]. These data must be taken as a lesson to learn for the future development of clinical guidelines and clinical pathways [9, 22, 29].

In a recent survey in Israel on the practice of DM, medical debriefing emerged as a significant way to reduce DM [7]. Virtually no physicians in our sample stated that medical debriefing would be effective. Around 5\% of the sample emphasised the need for strengthening physicians' ethical values in fighting the practice of DM. To the best of our knowledge, this is the first time that such a need has been reported. We believe this is an important finding that warrants further investigation.

The respondents agreed that there is a need for tortsystem reforms on medical negligence, which has emerged as a major problem to be solved at the healthcare-system level. Positive advances in this area will likely reduce the practice of DM. This confirmed a previously published recommendation on the need for tort reform in Italy [10, 22]. This result is consistent with the results of similar studies in other countries and with literature that suggests how medical malpractice reforms would reduce the costs of DM and litigation [5, 7, 13, 24, 30, 31]. Recent papers argued that physicians' attitudes about DM do not correlate with legal risk and criticised the possible effect of tort reform [20, 25]. We believe that tort reform is necessary, even though unlikely sufficient to eliminate the practice of DM, since half of the interviewed physicians did not mention it as the best system strategy [32]. Rather, a significant portion of the sample claimed that it would be better to promote a more positive public climate around physicians, with more emphasis on good practices and attention to physicians' rights. We believe this attitude change together with tort reform that incorporates a systematic use of evidence-based guidelines in courts could contribute to reducing the DM problem.

\section{Study limitations}

Rigorous measurement of the prevalence and costs of DM is elusive [31]. First, measurement and self- identification of practising DM are difficult, because distinctions between inappropriate and appropriate care are unclear in many clinical situations [2]. This is mainly due to the scarcity of objective methods for measuring DM [7, 32]. Moreover, it is impossible to measure the portion of unconsciously practised DM, because it originates from requests by other specialists or because it is incorrectly ordered due to ignorance of best-practices evidence [10]. The cost of DM is also difficult to estimate due to the different methods that have been used in the literature [13, $18,20,33]$. We believe this measurement issue is the major limitation of our study and indeed all studies investigating DM. We also recognise that other factors may affect DM rates, such as the enormous variation in the medical malpractice environment, and in the healthcare and welfare systems and legal institutions across countries [16]. This could also limit the generalisability of our findings.

Other limitations are related to the nature of study design. We sampled information about behaviour at a single point in time. This may be biased by the recall aspect of trying to remember behaviours not immediately being engaged. Self-reports can also be biased by concerns about reporting DM practices, including a 'socially desirable response bias' [12, 31, 32]. Together with unconsciously practised DM, this could lead to an underestimation of the prevalence of DM [5]. On the other hand, physician selfreports of DM could also be biased by overstating the frequency of benign DM practices [2].

Lastly, our study was performed at the hospital level. We believe that future research on DM should aim to replicate our findings in primary-care settings, in particular sampling the opinions of general practitioners $[4,33]$.

\section{v. Conclusions}

The present study shows how the practice of DM is very prevalent in Italian hospitals, is a significant factor contributing to healthcare costs, and provides no benefit to patients.

In conclusion, we believe that our study enriches the current literature on DM and that our findings may help inform discussions in countries where DM practices have not yet been evaluated. We also believe that the economic burden of DM on the public healthcare system could provide a substantial stimulus for a prompt review of this situation in a time of economic crisis [4, 10]. It is ours and others' opinion that DM is essentially immoral, and we hope that the findings of this study can be used by the Italian National Health Care System and by members of the medical community to demand change, reducing unnecessary risks for our patients and additional costs for our citizens.

\section{References}

[1] U.S. Congress, Office of Technology Assessment. Defensive Medicine and Medical Malpractice, OTA-H--6O2 (Washington, DC: U.S. Government Printing Office, July 1994).

[2] Studdert DM, Mello MM, Sage WM, DesRoches CM, Peugh J, Zapert K, Brennan TA. Defensive medicine among high-risk specialist physicians in a volatile malpractice environment. JAMA. 2005 Jun 1;293(21):2609-17. 
Proc. of The Fifirth Intl. Conf. On Advances in Economics, Management and Social Study - EMS 2016

Copyright (C) Institute of Research Engineers and Doctors, USA .All rights reserved.

ISBN: 978-1-63248-089-7 doi: 10.15224/ 978-1-63248-089-7-32

[3] Kessler DP, Summerton N, Graham JR. Effects of the medical liability system in Australia, the UK, and the USA. Lancet. 2006 Jul 15;368(9531):240-6.

[4] Ortashi O, Virdee J, Hassan R, Mutrynowski T, Abu-Zidan F The practice of defensive medicine among hospital doctors in the United Kingdom. BMC Med Ethics. 2013 Oct 29;14:42. doi: 10.1186/1472-6939-14-42.

[5] Sathiyakumar V, Jahangir AA, Mir HR, Obremskey WT, Lee YM, Apfeld JC, Sethi MK. The prevalence and costs of defensive medicine among orthopaedic trauma surgeons: a national survey study. J Orthop Trauma. 2013 Oct;27(10):592-7. doi: 10.1097/BOT.0b013e31828b7ab4.

[6] Panella M, Leigheb F, Rinaldi C, Donnarumma C, Tozzi Q, Di Stanislao F. Defensive Medicine: Overview of the literature. Ig San Pubb 2015 in press.

[7] Asher E, Greenberg-Dotan S, Halevy J, Glick S, Reuveni H. Defensive medicine in Israel - a nationwide survey. PLoS One. 2012;7(8):e42613. doi: 10.1371/journal.pone.0042613. Epub 2012 Aug

[8] Asher E, Dvir S, Seidman DS, Greenberg-Dotan S, Kedem A, Sheizaf B, Reuveni H. Defensive medicine among obstetricians and gynecologists in tertiary hospitals. PLoS One. 2013;8(3):e57108. doi: 10.1371/journal.pone.0057108. Epub 2013 Mar 6.

[9] Hiyama T, Yoshihara M, Tanaka S, Urabe Y, Ikegami Y, Fukuhara T, Chayama K. Defensive medicine practices among gastroenterologists in Japan. World J Gastroenterol. 2006 Dec 21;12(47):7671-5.

[10] Elli L, Tenca A, Soncini M, Spinzi G, Buscarini E, Conte D. Defensive medicine practices among gastroenterologists in Lombardy: between lawsuits and the economic crisis. Dig Liver Dis. 2013 Jun;45 (6):469-73. doi: 10.1016/j.dld.2013.01.004. Epub 2013 Feb 9.

[11] Nahed BV, Babu MA, Smith TR, Heary RF. Malpractice liability and defensive medicine: a national survey of neurosurgeons. PLoS One. 2012;7(6):e39237. doi: 10.1371/journal.pone.0039237. Epub 2012 Jun 22.

[12] Smith TR, Habib A, Rosenow JM, Nahed BV, Babu MA, Cybulski G, Fessler R, Batjer HH, Heary RF. Defensive medicine in neurosurgery: does state-level liability risk matter? Neurosurgery. $2015 \quad$ Feb;76(2):105-14. doi: 10.1227/NEU.0000000000000576.

[13] Sethi MK, Obremskey WT, Natividad H, Mir HR, Jahangir AA. Incidence and costs of defensive medicine among orthopedic surgeons in the United States: a national survey study. Am J Orthop (Belle Mead NJ). 2012 Feb;41(2):69-73.

[14] Keren-Paz T. Liability regimes, reputation loss, and defensive medicine. Med Law Rev. 2010 Autumn;18(3):363-88. doi: 10.1093/medlaw/fwq015. Epub 2010 Aug 11.

[15] Anderson BL, Strunk AL, Schulkin J. Study on defensive medicine practices among obstetricians and gynecologists who provide breast care. J Healthc Qual. 2011 May-Jun;33(3):37-43. doi: 10.1111/j.1945-1474.2010.00120.x. Epub 2010 Nov 11.

[16] Xu X, Spurr SJ, Nan B, Fendrick AM. The effect of medical malpractice liability on rate of referrals received by specialist physicians. Health Econ Policy Law. 2013 Oct;8(4):453-75. doi: 10.1017/S1744133113000157. Epub 2013 Mar 26.

[17] Mello MM, Studdert DM, Kachalia A. The medical liability climate and prospects for reform. JAMA. 2014 Nov 26;312(20):2146-55. doi: 10.1001/jama.2014.10705.

[18] Mello MM, Chandra A, Gawande AA, Studdert DM. National costs of the medical liability system. Health Aff (Millwood). 2010 Sep;29(9):1569-77. doi: 10.1377/hlthaff.2009.0807.

[19] Gomez V, Raimondo M. "Primum Non Nocere": are we getting carried away? Dig Liver Dis. 2013 Jun;45(6):462-3. doi: 10.1016/j.dld.2013.03.011. Epub 2013 May 3.

[20] Rothberg MB, Class J, Bishop TF, Friderici J, Kleppel R, Lindenauer PK. The cost of defensive medicine on 3 hospital medicine services. JAMA Intern Med. 2014 Nov;174(11):18678. doi: 10.1001/jamainternmed.2014.4649

[21] Catino M, Celotti S. The problem of defensive medicine: two Italian surveys. Stud Health Technol Inform. 2009;148:206-21.

[22] Fanos V, Tagliabue P, Greco L, Agostiniani R, Carbone MT, D'Agostino P, Correra A. Neonatal malpractice claims in Italy: how big is the problem and which are the causes? J Matern Fetal Neonatal Med. 2012 May;25(5):493-7. doi: $10.3109 / 14767058.2011 .622004$

[23] Dillman DA, Smyth JD, Christian LM. Internet, Mail, and Mixed-Mode Surveys: The Tailored Design Method. $3^{\text {rd }}$ ed. Hoboken, NJ: Wiley; 2009.

[24] Bishop TF, Federman AD, Keyhani S. Physicians' views on defensive medicine: a national survey. Arch Intern Med. 2010 Jun 28;170(12):1081-3. doi: 10.1001/archinternmed.2010.155.

[25] Waxman DA, Ridgely MS, Heaton P. The effect of malpractice reform on emergency department care. N Engl J Med. 2015 Jan 8;372(2):192. doi: 10.1056/NEJMc1413881.

[26] European Commission, Medical Errors, Special Eurobarometer 241 (2006), Bruxelles, European Commission.

[27] OIS, International Observatory of Health, Rome 2015 Jan 20. http://www.osservatorio-ois.com/wpcontent/uploads/dati_sondaggio_ois.pdf. Accessed 31 March 2015.

[28] National Institute of Health (Italy). National system guidelines (SNLG) http://www.snlg-iss.it/ Accessed 3 March 2015.

[29] Panella M, Marchisio S, Brambilla R, Vanhaecht K, Di Stanislao F. A cluster randomized trial to assess the effect of clinical pathways for patients with stroke: results of the clinical pathways for effective and appropriate care study. BMC Med. 2012 Jul 10;10:71. doi: 10.1186/1741-7015-10-71.

[30] Mello MM, Brennan TA. The role of medical liability reform in federal health care reform. N Engl J Med. 2009 Jul 2;361(1):1-3. doi: 10.1056/NEJMp0903765. Epub 2009 Jun 15.

[31] Studdert DM, Mello MM, Brennan TA. Defensive medicine and tort reform: a wide view. J Gen Intern Med. 2010 May;25(5):380-1. doi: 10.1007/s11606-010-1319-8

[32] Hermer LD, Brody H, Defensive medicine, cost containment, and reform. J Gen Intern Med. 2010 May;25(5):470-3.

[33] Brateanu A, Schramm S, Hu B, Boyer K, Nottingham K, Taksler GB, Jolly S, Goodman K, Misra-Hebert A, Vakharia N, Hamilton AC, Bales R, Manne M, Lathia A, Deshpande A, Rothberg MB. Quantifying the defensive medicine contribution to primary care costs. J Med Econ. 2014 Nov;17(11):810-6. doi: 10.3111/13696998.2014.959125. Epub 2014 Sep 12. 